\title{
FIT ACCURACIES OF THE SWING LOCK REMOVABLE PARTIAL DENTURE FRAMEWORKS CONSTRUCTED WITH TWO DIFFERENT DOUBLE CASTING TECHNIQUES
}

\author{
Aisha Z. H. Mustafa *
}

\begin{abstract}
Purpose: This article compares the fit accuracies of the swing lock metallic frameworks constructed with two different double casting techniques.

Material and methods: An experimental mandibular acrylic model with the only remaining 6 anterior teeth was constructed. 4 partial metallic frameworks of S/L RPD were constructed using two methods of the double casting technique. For standardization 4 lingual parts of S/LRPD was constructed to be used with the 2 groups. The 2 groups differed in the method of construction of the labial part either with or without reduplication of the master cast. A standard measure scope was used to measure in micrometer the fit of the labial part of each of the S/L RPD metallic framework to the model. The SPSS program was used for data analysis. Shapiro-Wilk test was used to test the normality of the data. Paired samples t-test was used to compare the fit of the two groups. $\mathrm{P}$ was significant if $<0.05$ at confidence interval $95 \%$.
\end{abstract}

Result: No significant difference was present between the two different methods for double casting technique of S/L RPD where $\mathrm{P}=0.062$.

Conclusion: The two methods for double casting technique results in an accurate casting, but the one without reduplicating the cast saves time.

Clinical implication: The double casting technique without reduplicating the cast saves the time.

KEYWORDS: Double casting, Swing lock, RPD.

\section{INTRODUCTION}

The swing lock is a unique dental prosthesis that gives good retention and stability as well as an excellent splinting especially with critical tooth forms, ${ }^{1-4}$ critical soft tissue shapes,${ }^{5}$ teeth with questionable prospects. ${ }^{6-8}$ It can be used in combination with an implant for partially edentulous patients ${ }^{9}$ or for maxillofacial prosthesis..$^{10-12}$ Also, it is used for a radiation carrier. ${ }^{13}$

* Lecturer, Department of Removable Prosthodontics, Faculty of Dentistry, Mansoura University. 
The swing-lock (S/L) removable partial denture (RPD) incorporates a hinged and locked labial bar that joins with the lingual part to form a stable and rigid framework for replacing missing teeth and gingival tissues. ${ }^{14}$ The labial bar, with I-bars, likes vertical bar projections projecting up to the gingival third of the enclosed teeth, swings from the hinge and snaps into the latch. When the prosthesis is in the latched position, all the enclosed teeth are splinted together and share in retention and stabilization of the prosthesis. ${ }^{15}$ The retentive mechanisms of $\mathrm{S} / \mathrm{L}$ RPD are rigid so that, they do not lose their retentive properties with use. Also, it is completely passive during insertion and removal of the prosthesis. ${ }^{16}$

One of the reasons that the S/L RPD is rarely used by clinicians is the sensitivity of the technique, especially during the hinge and lock, fabrication. ${ }^{17}$ The laboratory technique, for fabricating the hinge and latch has two choices. The first one is the single casting technique which requires only one refractory cast, one mold investment, and one casting to create mutually labial and lingual sections of S/L RPD metal framework. This technique uses the original mechanisms, hinge and latch, which are retained in the wax pattern by means of retentive outlines of the metal. The second one is the double casting technique that requires 2 refractory cast, 2 mold investments, and 2 casting; one to each of labial and lingual sections of S/L RPD. ${ }^{14}$ The double-casting method is more difficult but more precise and reliable than the conventional single casting method because it results in minimal errors. In addition to this, it allows creation of smaller and more accurate joints than one can achieve with commercial components. $^{18}$

Intraoral scanning technology was used to produce a stereolithographic file that was successively introduced into a computer-aided design software program for the digital design of a partial removable dental prosthesis framework. After that, computer-aided manufacturing was used for fabrication of a cast partial removable dental prosthesis. ${ }^{19}$
Rapid prototyping (RP) transform the 3D computer data into the custom-made compact models. RP manufacture technologies include stereolithography (SLA), computer numerical controlled (CNC) milling, fused deposition modeling (FDM), and, more recently, selective laser sintering (SLS). In dentistry the RP techniques are used for wax pattern fabrication for dental (facial) prostheses, and framework fabrication of removable dental prostheses. ${ }^{20}$ In the past, a removable partial denture (RPD) framework plastic pattern was produced using an RP machine, and then used as a conventional pattern. ${ }^{21,22,23}$ However with the introduction of the selective laser melting (SLM) technique, the metal frameworks of RPD can be directly constructed, thus eliminating the casting stage. The new RP techniques in the near future could change traditional prosthodontic applies. ${ }^{20}$ Clinical research studies are necessary to decide the efficiency of the CAD/ CAM RPDs treatment modality. ${ }^{24}$

RPD designs and construction using the CAD/ CAM provide improvement of fit, function, and esthetics. ${ }^{25}$ But the conventional method for the RPD construction still used currently.

The accurate fit of RPD framework is important to provide maximum function, aesthetic and stay biocompatible. ${ }^{26}$ A careful examination of the gaps or spaces between the frameworks and casts determine the accuracy of the fitting of the prosthesis before it is supplied to the patient. ${ }^{27}$ The accuracy of the framework constructed by using light-polymerizing plastic pattern was clinically satisfactory. This technique decreases the laboratory cost and time for removable partial denture construction..$^{28}$ The retentive unit constructed by the light-cured pattern had a better fit than that constructed by the conventional method. ${ }^{29}$

The effect of conventional wax or lightpolymerized patterns on the surface roughness and internal porosity of cobalt-chromium castings of PRD was revealed no differences between the two pattern materials. ${ }^{30}$ Framework fit can differ 
according to the construction technique. The fit of the frameworks fabricated of light-cured material was better than that fabricated with the traditional technique. ${ }^{31}$

Several types of research studied the gaps or spaces between the framework and casts to determine the amount of the fit..$^{32-39}$ The thickness of the elastomeric impression material that allowed to set in gaps was measured..$^{32}$ The framework and cast have been accurately maintained by the resin, then they were sectioned to expose gaps between the framework and cast..$^{33}$ Custom made feeler gauges was used to identify the gap under retentive ends of the clasps. ${ }^{34}$ The three main electronic methods for measuring small gaps are X-rays, Ultrasonic, and capacitive transducers. ${ }^{27}$ Also, the digital intraoral camera was used for imaging the gaps among the framework and the cast. Then graphic editing program was used for measuring the gaps on the images. ${ }^{31}$ A standard measurescope can be used for measurement of denture displacement $t^{40}$ in addition to measuring of the gaps between the denture and the model.

This article compares the fit accuracies of the S/L RPD metallic frameworks constructed with two different double casting techniques. The first technique is double casting with reduplication of the master cast. The second technique is double casting without reduplication of the master cast. The null hypothesis of this study was that the fit accuracies of the S/L RPD metallic frameworks constructed with two different double casting techniques were equivalent.

\section{MATERIAL AND METHODS}

Acrylic demonstration model of a mandibular arch with only 6 anterior teeth were used for constructing eight metal frameworks of S/L RPD with double casting techniques using two different methods. Each group includes 4 frameworks $(n=4)$. The sample size of four was used as guided by the research of de Franca, et al. ${ }^{38}$ For standardization
4 lingual parts of S/LRPD was constructed to be used with the 2 groups. The lingual section was casted with cobalt-chromium metal alloy (Biosil-F; Degussa, Hanau, Germany) then it was repositioned on the master cast (Fig. 1A) for the casting of the labial section with one of the two different methods of double casting technique.

In the first method of the double casting, reduplication of the master cast was done with the lingual section of casting remains on the master cast and in the duplicating agar (Fig. 1B). Then the investment material was poured against it. The refractory cast was hardened without removing the lingual casting then the labial section was waxed (Fig. 2) and "cast to" the lingual section. After casting, an index of the labial surface was made.

In the second method of the double casting, without reduplication of the master cast, the separating medium was applied to the labial surface of the master cast. A light-curing material was applied as a core for the labial part. Then complete the wax building of the labial bar component directly to the lingual section on the master cast. The waxing of labial part was guided by the index. After spruing, the lingual casting with waxed labial part was removed carefully from the master cast for investing and casting (Fig. 3 A, B).

After casting with either the first or the second

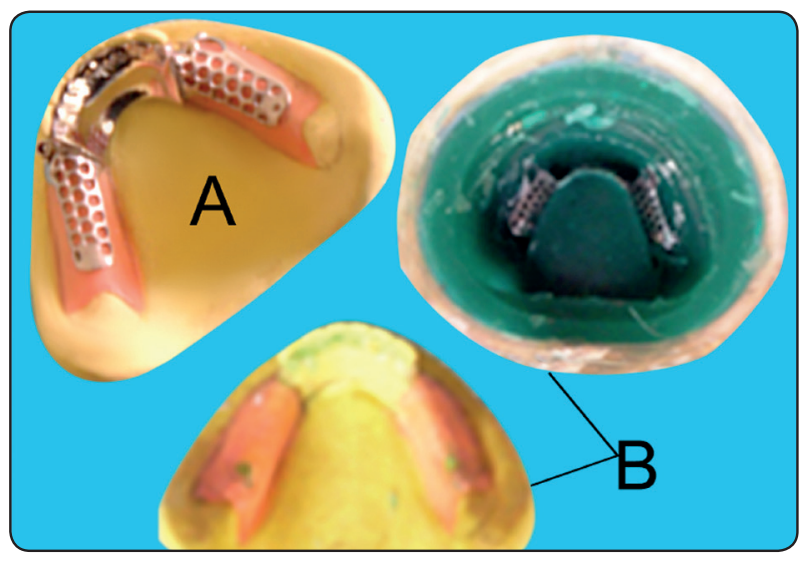

Fig. (1) A. The casted lingual part of casting is repositioned on the master cast. B. The lingual part of casting remains in duplicating agar. 
method, sprues and flashes on casting that may cross over or between the labial and lingual aspect around the hinge and lock attachments were removed before any attempt to open the prosthesis. Finish and elector polish were done before freeing the attachment. An instrument was used for trying to open the lock-latch combination. the S/L RPD framework was seated on the master cast and acrylic demonstration model (Fig. 4 A, B, C).

\section{Measuring the fit accuracies}

A standard measure scope E0020 (Monocular

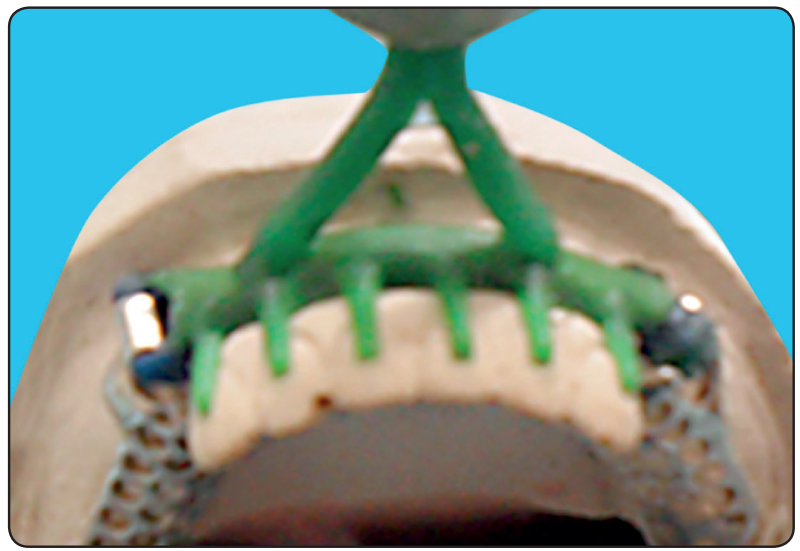

Fig. (2) Wax pattern of the labial bar component connected to the casted lingual part after spruing.

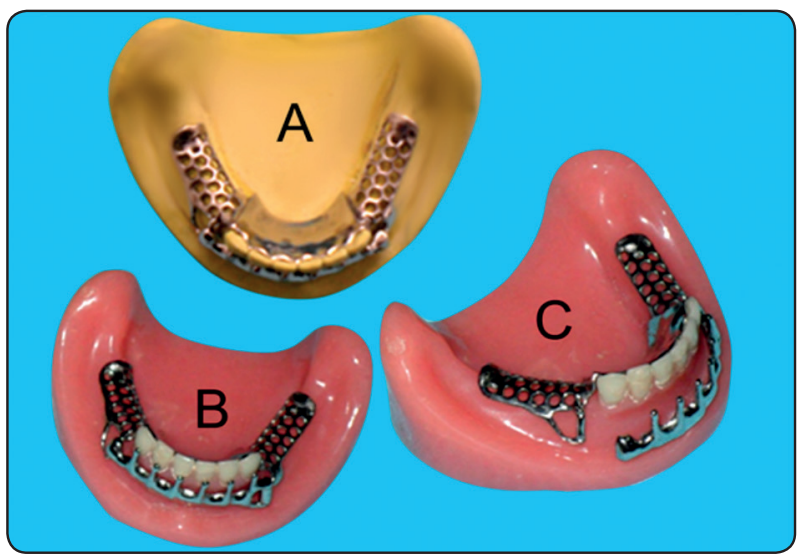

Fig. (4) A, Metallic framework of S/L RPD in closed position on master cast and $\mathrm{B}$, on the Acrylic demonstration model and $\mathrm{C}$, in opened position on the Acrylic demonstration model. measurescope type-10 Nikon- Japan) was used to measure the fit in micrometer of the labial part of each of the swing-lock removable partial denture metallic framework to the model (fig 5). The horizontal distance (gaps) between each of the vertical projections of the labial part and the abutment tooth of the model was measured. Three areas to measure the horizontal distance between a vertical projection and the abutment tooth of the model. These measurements averaged and treated as independent variables. These distances represent the amount of misfit.

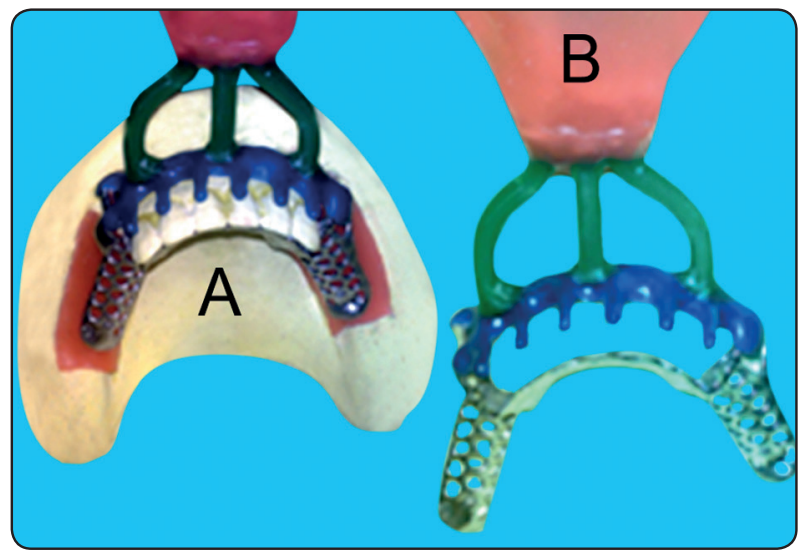

Fig. (3) A, The labial bar component wax pattern connected to the casted lingual part on the master cast directly then sprued. B, The wax pattern with the casted lingual part removed carefully from the cast for investing.

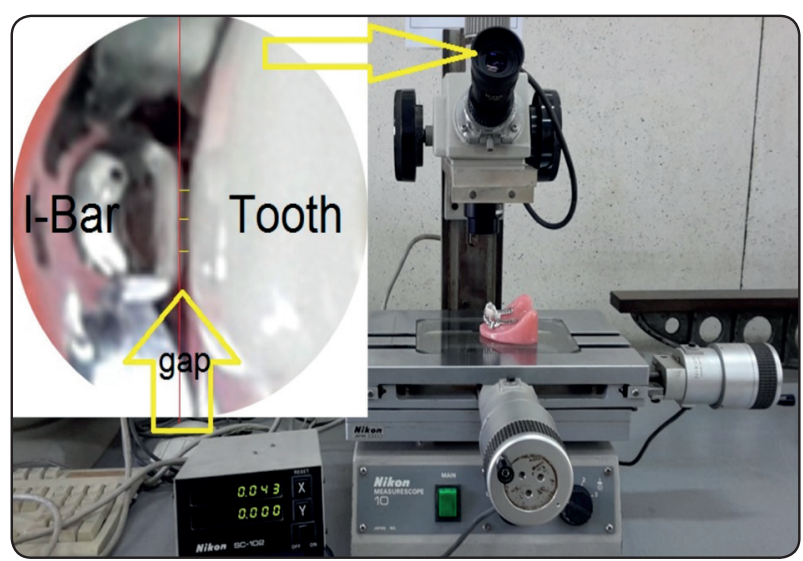

Fig. (5) The measurescope was used for measuring the gap between the vertical projection of the labial part and the teeth of the model. 
After construction of the S/L RPD framework using one of the methods that mentioned before, the fit accuracies of the labial part were measured. Then the labial section was sectioned and removed to allow construction of the S/L RPD framework using the other method on the same lingual part. Then the fit accuracies of the labial part were measured.

\section{Statistical analysis}

The SPSS statistical package for social science v.17 (SPSS Inc., Chicago, IL) was used for data analysis. Shapiro-Wilk test was used to test the normality of the data. The data was parametric and normally distributed. Paired samples t-test was used to compare the fit between the two groups S/L RPD with and without reduplication of the master cast. $\mathrm{P}$ was significant if $<0.05$ at confidence interval $95 \%$.

\section{RESUL}

The mean and standard deviation of measured gaps (in micrometer) for double casting technique with and without reduplication of the master cast were presented in (Table 1). No significant difference was present between the two different methods for double casting technique of S/L RPD where $\mathrm{P}=0.062$.

TABLE (1) The mean and standard deviation and statistical comparison of the measured gaps (in micrometer) for double casting technique with and without reduplication of the master cast.

\begin{tabular}{|c|c|c|}
\hline & $\begin{array}{c}\text { Measured gaps } \\
\text { of double casting } \\
\text { technique with } \\
\text { reduplication }\end{array}$ & $\begin{array}{c}\text { Measured gaps } \\
\text { of double casting } \\
\text { technique without } \\
\text { reduplication }\end{array}$ \\
\hline mean & 67.1 & 64.6 \\
\hline $\begin{array}{c}\text { Standard } \\
\text { deviation }\end{array}$ & $16.8 \pm$ & $16.7 \pm$ \\
\hline T value & \multicolumn{2}{|c|}{1.999} \\
\hline P value & \multicolumn{2}{|c|}{0.062} \\
\hline
\end{tabular}

*Significant different at $P \leq 0.05$.

\section{DISCUSSION}

Improvements in imaging, data processing and rapid prototyping technologies have allowed the fabrication of RPD framework patterns and/ or RPDs entirely in a new methodology. ${ }^{19-25}$. The conventional laboratory construction of the RPD is still used until now.

This in vitro study simplifies the conventional laboratory process for construction of S/L RPD. The construction of S/L RPD is more complex than that of a conventional RPD. ${ }^{17}$ The material of choice for S/L RPD framework should be cobalt- chromium alloys to provide rigidity, strength, and wear resistance that required for the hinge and locking mechanisms. ${ }^{15}$

The hinge and latch may be cast separately from prefabricated plastic patterns or purchased in already cast form. They are secured to the wax-up of the main framework being placed in the same horizontal plane and parallel to each other. A careful casting technique is require ${ }^{10}$ to avoid welding of the molten metal alloy to the precast hinge and latch mechanism and destroy the mechanism. In double casting technique of S/L RPD, the lingual section is cast firstly then it must be repositioned on the master cast for the second casting of the labial section. ${ }^{14}$ In this study, the second casting of the labial section can be done either with or without reduplication of master cast.

In the first method of this study, the reduplication of the master cast was done using agar reversible hydrocolloid material. The lingual section remains in the duplicating agar and the refractory material was poured against it. On this refractory cast, the labial component was waxed to the first lingual section. Then it was sprued and casted to the first casting. But in the second method, without reduplication of the master cast, after application of separating medium to the master cast the first lingual section remains on the master cast and a light curing resin was used directly to form a rigid core of the labial 
section with hinge and latch component. Blue inlay wax was used to complete the contouring. After spruing of this part, the latch opened carefully and the first casting with waxed labial part was removed from the master cast and was invested to casting the labial part.

A precise hinge and latch results from the double casting technique, since the thin oxide layer that formed on the first part of casting when it is placed in the furnace to burn out the second waxed up segment (labial bar), well create freedom of movement in hinge and latch. ${ }^{1}$ This technique gives the possibility to make smaller and more precise joints than one can achieve with commercial components.

The results of this study accept the null hypotheses, where there was no significant difference between the two different methods used for double casting of S/L RPD. The double casting method, without reduplicating the master cast, gives accurate casting as well as the double casting method, but it saves the time. Neither method was able to accomplish an optimal fit. One cause for the absence of complete fit is the high linear solidification shrinkage of cobalt-chromium based alloys. ${ }^{35}$ hence, it is difficult to achieve complete fit of the metal framework. ${ }^{31,36}$

The fit of the cobalt - chromium PRDP may be compromised by errors in wax blocking out and duplication, variability in the expansion of the refractory material, and the techniques used for fitting and polishing the metal frameworks. ${ }^{37}$ In the casting, the agar duplicating material is suffering dimensional variations of syneresis and imbibition, which may unfavorably affect the accuracy of the refractory cast. ${ }^{29}$ Therefore, it is practical to have an accurate fit with the second method because there is no reduplication of the master cast, and the light cured resin is adapted directly to the hinge and latch component in accurate position on the master cast.

The vertical misfit of a fabricated Co-Cr alloy framework was influenced by manufacturing technique. After definitive fit measurement, a better passive fit would be found for $\mathrm{Co}-\mathrm{Cr}$ frameworks processed by CAD/CAM technology in comparison with conventional casting. ${ }^{38}$ there are no any study that use the CAD/CAM technology in the swinglock RPD construction.

The result of this study found no difference between the two methods. This result was not in agreement with the studies ${ }^{29,31}$ that found a more accurate fit of the metal frameworks constructed with light cured resin in comparison to the conventional method. This may attribute to the difference in the prosthesis design and technique. In the other hand, Sushma $^{39}$ found that: the inlay wax pattern give better vertical marginal fit in comparison to the light cured modeling resin material and autopolymerized resin material.

One limitation of this in vitro study was that the fit accuracy was evaluated just at the vertical projection of the labial bar. Further investigation is required to study the fit accuracy of all the labial part including the hinge and latch to detect the meticulous area of the interference. In addition, an in vivo study of the fit accuracy must be made, to notice whether it is clinically tolerable. Also, it is interesting to compare the fit accuracy of S/L RPD constructed by the use of the CAD/CAM technology with that constructed with the double casting method.

\section{CONCLUSION}

Within the limitation of this study, the double casting method, without reduplicating the master cast for the second casting, gives accurate casting as well as the double casting method, with reduplicating the master cast but it saves the time. This double casting technique can be used with many prosthetic devices other than a swing-lock removable partial denture such as stress breaker removable partial denture (hidden-lock), disjunct denture, and metallic framework constructed on fixed crown or bridge before cementation of crown or bridge. 


\section{CONFLICT OF INTEREST}

No conflict of interest.

\section{ACKNOWLEDGEMENT}

Author thanks Prof. Ibrahim Elewa (Professor of Industrial Production Engineering, Faculty of Engineering, Mansoura University) for his guidance in the measurement of the fit accuracy.

\section{REFERENCES}

1. Brudvik JS. Advanced Removable Partial Dentures. Chicago: Quintessence; 1999.p. 107-10.

2. Antos EW, Renner RP, Foerth D. The swing-lock partial denture: An approach to conventional removable partial denture service. J Prosthet Dent 1978;40:257-62.

3. Schulte JK, Smith DE. Clinical evaluation of swinglock removable partial dentures. J Prosthet Dent 1980;44:595603.

4. Sadig W, Fahmi F. 5 modified swing-lock: A new approach. J Prosthet Dent 1995;74:428-31

5. Barclay CW, Russell MD, Murphy P. A three- part bilateral swing lock design denture revisited. Case report. Br Den J 2001;190:538-40.

6. Car AB, Brown DT. McCracken's Removable partial prosthodontics. 12 ${ }^{\text {th }}$ ed. St. Louis: Elsevier Mosby; 2011. p. $38,333-334,341$.

7. Roberts HW. Swing-lock partial dentures. Gen Dent 2001;49:366-72.

8. Lynch CD, Allen PF. The swing-lock denture: its use in conventional removable partial denture prosthodontics. Dent Update 2004;31:506-8.

9. McAndrew R. Prosthodontic rehabilitation with a swinglock removable partial denture and a single osseointegrated implant: A clinical report. J Prosthet Dent 2002;88: 128-31.

10. Bolender CI, Becker CM. Swing-lock partial denture where and when. J Prosthet Dent 1981;45:4-10.

11. Talbot TR. Review of swing-lock partial denture. Int $\mathbf{J}$ Prosthodont 1991; 4: 80-8.

12. Turkyilmaz I. Prosthodontic management or patient with cleft lip/palate using maxillary overdenture and swinglock attachment mechanism. Clinical report. N Y State Dent J 2008;74:62-4.
13. Ersu B, Hekimoglu C, Özyar E, Aslan Y. A hinged flange radiation carrier for the scalp: A clinical report. J Prosthet Dent 1998;79:369-71.

14. Rudd KD, Morrow RM, Eissmann HF. Dental laboratory procedures. Removable partial dentures. Vol 3. St. Louis: Mosby; 1981. p. 491-524.

15. Phoenix RD, Cagna DR, DeFreest CF. Stewart's Clinical removable partial prosthodontics. $3^{\text {rd }}$ ed. Chicago: Quintessence; 2003. p. 398-506.

16. Cameron DA, Lyons MF. Properties of a custom-made hinge clasp compared with a conventional circumferential clasp. J Prosthet Dent 1996;75:326-31.

17. Schwalm CA, La Spina FV. Fabricating swing-lock removable partial denture frameworks. J Prosthet Dent $1981 ; 45: 216-20$.

18. Minagi S, Tanaka T, Sato T, Matsunaga T. Double-casting method for fixed prosthodontics with functionally generated path. J Prosthet Dent 1998;79:120-24.

19. Kattadiyil MT, Mursic Z, AlRumaih H, Goodacre CJ. Intraoral scanning of hard and soft tissues for partial removable dental prosthesis fabrication. J Prosthet Dent 2014;112:444-8.

20. Beguma, Z. and P. Chhedat, Rapid prototyping--when virtual meets reality. Int J Comput Dent 2014;17: p. 297-306.

21. Bibb RJ, Eggbeer D, Williams RJ, Woodward A. Trial fitting of a removable partial denture framework made using computer-aided design and rapid prototyping techniques. Proc Inst Mech Eng H 2006; 220: p. 793-7.

22. Eggbeer D, Bibb R, Williams R. The computer-aided design and rapid prototyping fabrication of removable partial denture frameworks. Proc Inst Mech Eng H. 2005;219:195-202.

23. Williams RJ, Bibb R, Rafik T. A technique for fabricating patterns for removable partial denture frameworks using digitizedcasts and electronic surveying. J Prosthet Dent 2004;91(1):85-8.

24. Lang LA, Tulunoglu. A critically appraised topic review of computer-aided design/computer-aided machining ofremovable partial denture frameworks. Dent Clin North Am 2014;58:247-55.

25. Bohnenkamp, D.M., Removable partial dentures: clinical concepts. Dent Clin North Am 2014;58:69-89.

26. Dunham D, Brudivik J, Morris J, Plummer K, Cameron $\mathrm{S}$. A clinical investigation of the fit of removable partial 
dental prosthesis clasp assemblies. J Prosthet Dent 2006; 95:323-6.

27. William RJ, Al-Hourani TR. An Electronic method for measuring the fit of removable partial denture frameworksz to dental casts. The journal of engineering research 2009;6:15-20.

28. Takaichi A, Wakabayashi N, Igarashi Y. Prefabricated lightpolymerizing plastic pattern for partial denture framework. Contemp Clin Dent 2011;2:402-4.

29. Kumar MV, Murugesan K, Bhagath SN. The accuracy of fit of cast clasps designed with conventional wax pattern and light cured patterns: a comparative in vitro study. SRM Univ. J. Dent. Sci. 2010;1:10-3.

30. Swelem AA, Abdelnabi MH, Al-Dharrab AA, AbdelMaguid HF. Surface roughness and internal porosity of partial removable dental prosthesis frameworks fabricated from conventional wax and light-polymerized patterns: a comparative study. J Prosthet Dent 2014;111:335-41.

31. Anan MT, Al-Saadi MH. Fit accuracy of metal partial removable dental prosthesis frameworks fabricated by traditional or light curing modeling material technique: An in vitro study. The Saudi Dental Journal 2015;27:149-54.

32. Stern MA, Brudvik JS, Frank RP. Clinical evaluation of removable partial denture rest seat adaptation. J Prosthet Dent 1985;53:658-62.
33. Fritell DN, Muncheryan AM, Green AJ. Laboratory accuracy in casting removable partial denture frameworks. J Prosthet Dent 1985;54:856-62.

34. Murray MD, Oyson JE. A study of clinical fit of cast cobaltchromium clasps. J Prosthet Dent 1988;16:135-9.

35. Anusavice KJ, Shen C, Rawls HR. Philips' Science of dental materials. $12^{\text {th }}$ ed. Elsevier Saunders Inc., 2012.p.199-386.

36. Gebelein M, Richter G, Range U, Reitemeier B. Dimensional changes of one-piece frameworks cast from titanium, base metal, or noble metal alloys and supported on telescopic crowns. J Prosthet Dent 2003;89:193-200.

37. Brudvik JS, Reimers D. The tooth-removable partial denture interface. J Prosthet Dent 1992;68:924-7.

38. de Franca DG, Morais MH, das Neves FD, Barbosa GA Influence of $\mathrm{CAD} / \mathrm{CAM}$ on the fit accuracy of implantsupported zirconia and cobalt-chromium fixed dental prostheses. J Prosthet Dent 2015;113:22-8.

39. Sushma R, Farias A, Soni R. Vertical marginal discrepancies of metal castings obtained using different pattern materials: A scanning electron microscope study. J Int Clin Dent Res Organ 2014;6:98-102.

40. Javid NS, Michael CG, Mohammed HA, Colaizzi FA. Three- dimensional analysis of maxillary denture displacement during reline impression procedure. J Prosth Dent 1985; 54: 232- 237. 